\title{
ENHANCING OUT-OF-CLASS COMMUNICATION
}

\author{
STUDENTS' PERSPECTIVES
}

\section{Bonnie S. Farley-Lucas, Margaret M. Sargent, Southern Connecticut State University}

Out-of-class communication between faculty and students is linked to student learning, engagement, and success. As the source for mentoring, advising, and supplemental instruction, out-of-class communication and its barriers require explicit attention. Using a faculty-student collaborative research approach, we interviewed a diverse group of thirty-three undergraduates regarding behaviors, statements, and practices that contributed to or discouraged out-of-class communication. We found that in-class communication sets the stage for whether students approach faculty outside class and that faculty misbehaviors and disconfirming communication in class almost inevitably lead to out-of-class avoidance.

Out-of-classroom communication is the wellspring for mentoring, academic advising, supplemental instruction, and, generally, favorable student-faculty relations. Out-of-class communication also includes faculty involvement in student organizations and all student-faculty discussions about non-class-related issues (Nadler \& Nadler, 2001). Many universities require faculty office hours to facilitate this essential contact. Despite its central role in academic culture, out-of-class communication, particularly from a student perspective, receives less explicit research attention than it deserves. This chapter examines personal characteristics

Our thanks to the reviewers of the manuscript for this chapter for helpful feedback and to Southern Connecticut State University student interviewers Kierstin Pry, Allison Stankiewicz, and Lissette Agosto. This project was supported by a 2009 Connecticut State University Research Grant. 
and behaviors of faculty that students experienced as contributing to, discouraging, or supporting out-of-class communication. Information gathered from students can help faculty attend to areas known to have a positive impact on teaching and can help faculty developers assemble workshops and professional resources to promote specific strategies that students experienced as helpful in their learning.

\section{Student-Faculty Communication}

Student-faculty communication is central to teaching and learning. Students rank student-faculty interaction as a high priority (Astin, 1993). They want to connect with professors and often cite the valued relational qualities of equality, mutuality, and respect (Garko, Kough, Pignata, Kimmel, \& Eison, 1994). When students engage in out-of-class communication, studentteacher relationships are more interpersonal in nature (Dobransky $\&$ Frymier, 2004; Fusani, 1994). Indeed, one of the two environmental factors most predictive of positive change in college students' academic development, personal development, and satisfaction, and one of the five benchmarks of student engagement, is interaction between faculty and students (Astin, 1993; Kuh, Kinzie, Schuh, \& Whitt, 2005; Light, 2001). Expressing care, building rapport, and creating positive learning climates all contribute to positive faculty-student interaction, and thus to student motivation and learning (Ambrose, Bridges, DiPietro, Lovett, \& Norman, 2010; Chickering \& Gamson, 1987; Meyers, 2009; Richmond, Gorham, \& McCroskey, 1987). Because faculty-student interaction promotes student motivation and success, professors are advised to increase contact, maximize office hours, talk with students, and share experiences (McKeachie \& Svinicki, 2010; Schoenfeld \& Magnan, 2004).

Despite its many benefits, face-to-face faculty-to-student out-of-class communication is infrequent (Feldman \& Newcomb, 1996). On average, first-year students interact with teachers outside class only once or twice a month, and seniors at research universities had no more interaction with faculty than first-year students did at liberal arts colleges (Schroeder, 2003). Electronic consultations by e-mail have largely replaced traditional office hours. Students favor e-mail contact with faculty for the ability to clarify course material, efficiency, availability, approachability, and personal and social reasons (Kelly, Keaten, \& Finch, 2004; Waldeck, Kearney, \& Plax, 2001). Faculty favor e-mail contact for efficiency, timeliness, ability to allow reticent students to communicate more freely, and potential for increased student engagement outside class (Duran, 
Kelly, \& Keaten, 2005). Given the primacy of e-mail contact, faculty face new challenges in building rapport with students.

Unfortunately, students do not always encounter positive faculty behavior. Teacher misbehaviors are defined as "those behaviors that interfere with instruction, and thus, learning" (Kearney, Plax, Hays, \& Ivey, 1991, p. 310). Based on their analysis, Kearney et al. identified twenty-eight categories of misbehavior within three underlying dimensions: incompetence, indolence, and offensiveness. Incompetence, which refers to the lack of basic teaching skills, has nine categories of misbehavior: confusing lectures, apathy toward students, unfair testing, boring lectures, unintelligible accents, information overload, lack of knowledge on subject matter, inappropriate volume, and bad grammar or spelling. Offensiveness relates to how teachers verbally interact with students and encompasses sarcasm, put-downs, verbal abuse, unreasonable or arbitrary rules, sexual harassment, negative personality, favoritism, and prejudice. Indolence, a teacher's disregard for students, refers to being absent, tardy, unprepared and disorganized, deviating from the syllabus, returning student work late, and information overload.

Faculty misbehaviors have a negative impact on both students and faculty. Students report less learning, less engagement, and less enactment of recommended classroom behaviors when teachers misbehave (Dolin, 1995). Furthermore, students often interpret teacher misbehavior. as intentional, and student motivation and judgments of teachers' effectiveness are both adversely affected by misbehavior (Kelsey, Kearney, Plax, Allen, \& Ritter, 2004). Teacher misbehaviors are also linked to student resistance (Kearney, Plax, \& Burroughs, 1991), teachers' lack of credibility (Banfield, Richmond, \& McCroskey, 2006), and negative teaching evaluations (Schrodt, 2003). Assertiveness, responsiveness, student liking for the teacher, and affect toward the material are all negatively associated with teacher misbehavior (Banfield et al., 2006; McPherson, Kearney, \& Plax, 2003, 2006; Myers, 2002; Wanzer \& McCroskey, 1998).

Not surprisingly, students can encounter teacher misbehaviors out of class as well as in class. Such misbehaviors include inaccessibility to students, missing scheduled appointments, not showing up for office hours, and not making time for students when they need additional help (Kearney et al., 1991). Although there is scant research on faculty misbehaviors in out-of-class communication, the anticipated consequences can be quite negative. Common problems associated with e-mail contact include lack of response to requests for project clarification, impersonal responses 
to students' reports of illness or family emergencies, and condescending comments on students' work. Students can experience barriers to learning, public embarrassment, sexual harassment, frustration, and the violation of expectations for faculty professionalism, all contributing to impoverished learning (Farley-Lucas \& Sargent, 2007).

\section{Research Approach}

This study aims to add depth to our understanding of out-of-class communication by privileging students' voices and highlighting their experiences. With an explicit focus on specific behaviors, interactions, and verbal statements that students experienced and defined as encouraging and discouraging of out-of class communication, we can make clearer connections to pedagogical practices that contribute to learning as well as to practices that contribute to disengagement, demotivation, and depersonalization. Specifying behaviors also allows an exploration of the nature, development, and consequences of particular classroom dynamics.

We addressed three key questions that emerged from the literature: (1) What personal characteristics and faculty behaviors have students experienced as encouraging out-of-class communication? (2) What personal characteristics and faculty behaviors have students experienced as discouraging out-of-class communication? and (3) What specific instructional strategies did students report as being effective in encouraging them to engage in out-of-class communication with their professors?

\section{Method}

To foster candid interviews and student research experience, three undergraduate interviewers were recruited, trained, and provided with uniform interview protocols. Each interviewed eleven undergraduates. When recruiting volunteers, they aimed for intentional diversity (Anderson $\&$ Jack, 1991), identifying and selecting participants for diversity of age, gender, ethnicity, major, and universities attended. Due to their limited experience with student-faculty communication, first-year students were not as heavily recruited as upperclass students. To protect identities, participants were asked to think about particular professors but avoid using names. To enhance anonymity, participants created their own pseudonyms, and tapes were submitted directly to a professional transcriptionist. Audiorecorded interviews averaged thirty-five minutes each, resulting in 402 pages of verbatim transcripts. 


\section{Participants}

Thirty-three undergraduate students, representing a diverse population, participated. There were sixteen women and seventeen men. Selfdescribed ethnicity identified Caucasian or white (eighteen), Hispanic (six), African American (two), Native American (one), Polish (one), "black and white" (one), "a regular walking U.N." (one), and three who declined to label themselves. Ages ranged from 19 to 32 , with an average of 21.8 years. Sixteen majors were represented: thirteen in arts and humanities; ten in social sciences; seven in science, engineering, and mathematics disciplines; and three in education. Sixteen participants attended the same university only, fourteen were transfer students representing twelve institutions, and three attended other universities. Participants were two first-year students, eight sophomores, nine juniors, and fourteen seniors.

\section{Analysis}

Narrative analysis focuses on describing people's varying experiences and highlights participants' own languages and definitions (Geertz, 1983). Using inductive analysis (Anderson \& Jack, 1991), interview transcripts were analyzed first to identify themes and trends for each participant, and then to identify themes and patterns across research questions. While participants varied in degree of detail provided, their experiences point to a wide variety of behaviors and instructional practices. Exemplars were selected according to three criteria: representativeness, the degree to which comments represent common perspectives or describe problematic interactions others experienced (similar views); intensity, the degree to which language reflects emotional, cognitive, or behavioral attachment to the category (strong views); and uniqueness, the degree to which comments capture unique viewpoints not previously expressed (different views) (Van Manen, 1990). Students' descriptive language adds authenticity to the study (Manning, 1997).

\section{Behaviors Encouraging Out-of-Class Communication}

Research question 1 addressed faculty's personal characteristics and behaviors that encourage students to engage in out-of-class communication. As seen in Table 6.1, participants provided 174 comments related to encouraging out-of-class communication, with ten key qualities discernable. Very clearly, in-class communication sets the stage for whether students approach faculty outside of class. 


\section{Table 6.I Qualities That Encourage Out-of-Class Communication}

Characteristic

Positive personal qualities

Invited out-of-class

communication

Caring

Offered or provided

instrumental help

Positive interpersonal skills

Availability

Challenging

Express or discuss common interest

Good teacher in class

Recognizes students as individuals
Number of Students Number of Statements $(n=33)$ $(n=174)$

21

36

21

29

16

29

14

20

10

13

8

16

7

11

7

8

5

4

4

Prior to outside connections, teachers must connect with students in class. Students variously described the most important characteristic that led them to engage in out-of-class communication as "showed empathy" or "caring about what students are dealing with." Those who showed interest in students' lives, and particularly those who showed interest in student success beyond classroom boundaries, received high praise. As one student commented, "She really wants you to understand and do well, not just for class." Along with caring behaviors, positive personal qualities encouraging interaction include "nice," "honest," "great sense of humor," "down to earth," "open," and "friendly." Similarly, faculty described as having good interpersonal skills, especially being a "good listener," encouraged out-of-class communication.

The most accessible teachers were described as inviting out-of-class communication, both implicitly and explicitly. Implicit invitations took the form of "being approachable" or "giving off that inviting feeling that we could meet anytime." Explicit invitations mostly stemmed from classroom introductions during the first class, with faculty actively creating a positive classroom climate. Often mirrored in the course syllabus, statements concerning the teacher's commitment to student success and expectations for conversations beyond classrooms were seen as indicative of 
teachers' welcoming student contact. Typically approachable teachers provided more time than official office hours, offering help at any time. Several reported teachers who invited feedback by e-mail or phone, and a few reported text messages.

Helpfulness was the next key theme. Once students approached professors out of class, they expected to receive the help they sought. Students reported receiving tangible assistance on projects, essays, and exams that led to improved understanding and, quite often, higher grades. Helpfulness extended to "being resourceful" and referring students to other on-campus resources.

Students are more likely to engage in out-of-class communication with faculty perceived as recognizing their individual needs. They appreciated faculty knowing their names and being aware of any special circumstances the students might be dealing with. Students shared positive anecdotes of faculty helping them cope with illness or absences, develop study strategies, and take advantage of opportunities to raise grades. At the same time, students are likely to engage in out-of-class communication with professors who challenge students, "raise the bar," and help students improve. As one stated, “They push you along, but don't hold your hand."

Positive out-of-class communication often transforms impersonal connections into more personal, caring relationships. With established lines of communication, students are more likely to present a positive face. They are more likely to care about professors' impressions of them, so they are less likely to miss class, and if they do, they are likely to provide justification. Professors who respond in caring ways to students' reports of illness or family or work demands further establish positive relational connections.

Quite often, students reported a relational shift that occurred when they could discuss more personal issues with instructors. Some reported seeing professors as potential mentors and advisors, and many established informal mentorships as a result of continued positive out-of-class communication. Some gained empathy and noted personal issues that professors were experiencing, such as losing a family member. Moreover, in positive student-faculty relationships, students reported working harder in class, gaining self-confidence, learning more about the discipline, and, in some cases, learning how to write or conduct research.

Student expectations of student-faculty relationships appear to undergo a transition from their first year through their senior year. During the first year, students reported feeling insecure, intimidated by faculty, and unsure how to connect. Therefore, faculty who facilitated 
interaction were evaluated highly. Some were described as "the reason I stayed" within academic programs or universities. Students in their third and fourth years were more likely to see faculty as individuals and more likely to engage in conversations about career-related or personal topics. More experienced students defined student-faculty relationships more instrumentally, particularly as they sought career-related information, networking, and letters of recommendation.

\section{Behaviors Discouraging Out-of-Class Communication}

Research question 2 explored behaviors and qualities discouraging out-ofclass communication. As seen in Table 6.2, 105 statements related to discouraging out-of-class communication, yielding eight key qualities. Only one student out of the thirty-three participants reported that she had not experienced negative interactions with faculty. The other thirty-two participants described a wide variety of faculty misbehaviors, negative interactions, and unprofessional actions that led to less-than-optimal learning outcomes. The primary finding is that faculty misbehaviors and disconfirming communication in class almost inevitably lead to out-of-class avoidance.

When describing professors they would be most unlikely to interact with outside class, students first centered on negative personal characteristics:

\section{Table 6.2 Qualities That Discourage Out-of-Class Communication}

Characteristic

Number of Students
$(n=33)$$\quad \begin{gathered}\text { Number of Statements } \\ (n=105)\end{gathered}$

Lack of availability/

unapproachable

Teacher misbehavior

Lack of interpersonal skills

Public embarrassment

Negative personal characteristics

Poor teaching

Lack of openness

Apathy toward students and teaching 
"cold," "arrogant," "self-centered," egotistical," "standoffish," and "mean." Negative teachers were described as possessing a lack of warmth and empathy and as having poor interpersonal skills. Exemplars included "doesn't start conversations" and "can't talk to him due to his lack of eye contact."

Unapproachable professors projected that they "disliked students," communicated a lack of openness ("he looked like he didn't have time for us"), and, in some cases, explicitly stated their lack of availability. As one explained, "On the first day of class she told us all the ways to contact her that she would never respond." Unapproachable faculty are seen as "not helpful." In some cases, faculty made statements discouraging communication, such as, "I'm not here to be your friend," or, "If you have problems, take it to your TA and not me."

The other main finding regarding discouraging out-of-class communication was that poor teaching was associated with faculty misbehavior. Students reported emotional memories of faculty members who were condescending, "shot down my ideas in class," or "told me my ideas are wrong." Most damaging were personal insults and negative comments about students' intelligence or academic ability. Public embarrassment, dismissive comments, lack of respect for students, and threatening students with poor grades were commonly cited as strong repellents to out-of-class communication. Inappropriate humor or humor made at the expense of students was also likely to discourage out-of-class contact. Poor teaching, including lack of organization, unclear assignments, and nonspecific expectations for evaluation of assignments often contributed to an overall evaluation of "lack of professionalism." Often unprofessional behavior was associated with professors' lack of concern for learning. One student recalled a professor who "expected you to know everything" yet did not provide means to learn.

Apathy emerged as the last main characteristic with a negative impact on out-of-class communication. Students often expect professors to demonstrate both passion for their discipline and concern for students. Professors who "seemed unhappy" or "showed a lack of passion for their subject" were evaluated negatively. The overarching assumption was, "Professors should display passion, not work just to get a paycheck." Apathy toward students was reflected in the following: "He just writes on the board and doesn't care to interact with us. He doesn't care about us." Students logically conclude that apathy in class would be equated with apathy out of class, and apathetic faculty do not inspire further contact. 
Students who experience negative in-class communication are less likely to pursue out-of-class contact and therefore less likely to experience learning, student success, and connectedness to a discipline. Students in this unfortunate position are presented with two negative outcomes: poor teaching and the lack of means to address the poor teaching. This dynamic is critical in students' first year because it may set expectations for more difficult or unprofessional professors, thus interfering with student success and retention.

With negative in-class communication, students reported less motivation to attend class or work on class assignments. This was particularly true if students experienced feelings of futility-that regardless of their effort, they would be graded harshly and receive a poor grade. Thus, students reported a higher likelihood of disengaging from the learning process. With respect to professors who repeatedly engage in student putdowns, the implicit message sent to students was that they should mimic professors' views in order to "survive a class," or, as one student said, "If you don't have the same opinion, you'll fail the class."

\section{Strategies for Encouraging Out-of-Class Communication}

Research question 3 explored specific instructional strategies students reported as effective in encouraging out-of-class communication with professors. They provided several concrete suggestions that faculty can use to inform their practice. Most obviously, faculty need to be present for office hours, keep scheduled appointments, and make time for students when they need help. Students expressed great appreciation for positive, one-on-one time, particularly when they received the help they expected. To facilitate "quick questions" when students are most likely to have them and allow brief exchanges, students expect professors to arrive early to class and stay after class.

Classroom management practices also contribute to out-of-class communication. Students responded well to syllabus statements inviting students to visit during office hours. Including a "by appointment" option is critical since it is quite likely that professors' office hours conflict with students' class or work schedules. Letting students know on the first day, with regular reminders throughout the semester, about availability for extra help was reassuring. Several students pointed out faculty who wrote their e-mail and office hours on the board every class. They were impressed by faculty who seemed to provide a "24/7 open door" by providing home phone numbers or cell phone numbers in case students ran into "emergencies." Although students "hardly ever" telephone a professor, they found 
this invitation to be a caring gesture. One student succinctly suggested, "Let us know that you enjoy talking with us, particularly about the course."

Students expect "respect," "positivity," and "professionalism" during class. When professors learned and used students' names, they felt "more valued," "more connected," and more likely to interact out of class. Students also suggested that faculty recognize and greet students when they encounter them around campus, and, if possible, exchange basic pleasantries.

Given that e-mail is the primary channel for academic and social connections, it is imperative that faculty respond promptly and politely. In addition to brief responses, a friendly opening and closing personalizes the communication. Students reported faculty sending periodic e-mails to the class offering assistance on projects as they progressed throughout the semester. Updates from faculty were seen as "very helpful" and as having a positive impact on students' performance. Blackboard and other learning management systems easily facilitate such contact.

In order to increase opportunities for one-on-one exchanges, students responded well to mandatory meetings. A few mentioned mandatory initial "meet-and-greets" held early in the semester to get acquainted and set goals. Midterm consultations held with each student to review progress helped motivate them to participate in class and earn higher grades. Oneon-one meetings provided specific feedback on course projects. Students allowed to submit revisions prior to assigning a final grade on projects reported learning more about the writing process.

\section{Discussion and Implications}

In summary, explicit descriptions of students' experiences contribute to our awareness of classroom interactions and instructional practices that either encourage or discourage out-of-class communication and the related outcomes of each. Positive out-of-class communication begins inside the classroom with the level of competence a professor demonstrates, as well as students' perceptions of professors' caring and helpfulness. Outside the classroom, students benefit from faculty described as approachable and helpful and those who recognize students as individuals. Positive out-of-class communication transforms student-faculty relations from impersonal to interpersonal, opening doors for mentoring and advising. Conversely, professors' disconfirming communication and misbehaviors inside the classroom inevitably lead to out-of-class avoidance. Poor teaching is associated with faculty misbehavior and 
contributes to poor academic achievement and disengagement from the learning process. Students' specific suggestions for instructional practices are helpful for those wishing to engage students in academic discourse, facilitate deeper understanding, and serve as advisors and mentors.

This study complements literature highlighting the importance of outof-class communication and the affective dimension of instruction, and it privileges students' perspectives. By identifying from a student perspective what constitutes positive out-of-class communication, faculty-student relationships, advisement, and mentoring can be strengthened. Associated outcomes are increased academic success, greater levels of integration and retention, more engaged learning, and increased satisfaction with academic experiences.

True to our intent, information gained from students was instrumental in developing workshops and resources that have been widely disseminated throughout our university. One workshop on out-of-class communication was conducted for faculty as part of our semester-wide offerings, and another workshop on best practices in student advisement was copresented with the academic advising office during our annual teaching academy. A short article was included in our faculty development electronic newsletter. A summarized list of students' top ten suggestions was included on the back of brochures distributed at a presemester faculty development forum and is included in new faculty orientation programs. Ultimately, faculty developers and faculty need to involve students and have a positive impact on them.

\section{REFERENCES}

Ambrose, S. A., Bridges, M. W., DiPietro, M., Lovett, M. C., \& Norman, M. K. (2010). How learning works: Seven research-based principles for smart teaching. San Francisco, CA: Jossey-Bass.

Anderson, K., \& Jack, D. C. (1991). Learning to listen: Interview techniques and analysis. In S. B. Gluck \& D. Patai (Eds.), Women's words: The feminist practice of oral history (pp. 11-26). New York, NY: Routledge.

Astin, A. W. (1993). What matters most in college? Four critical years revisited. San Francisco, CA: Jossey-Bass.

Banfield, S. R., Richmond, V. P., \& McCroskey, J. C. (2006). The effect of teacher misbehaviors on teacher credibility and affect for the teacher. Communication Education, 55(1), 63-72. doi:10.1080/03634520500343400

Chickering, A. W., \& Gamson, Z. F. (1987, March). Seven principles for good practice in higher education. AAHE Bulletin, 39(7), 3-7. 
Dobransky, N. D., \& Frymier, A. B. (2004). Developing teacher-student relationships through out of class communication. Communication Quarterly, 52(3), 211-223. doi:10.1080/01463370409370193

Dolin, D. J. (1995). Ain't misbehavin': A study of teacher misbehaviors, related to communication behaviors, and student resistance (Unpublished doctoral dissertation). West Virginia University, Morgantown.

Duran, R. L., Kelly, L., \& Keaten, J. A. (2005). College faculty use and perceptions of electronic mail to communicate with students. Communication Quarterly, 53(2), 159-176. doi:10.1080/01463370500090118

Farley-Lucas, B. S., \& Sargent, M. M. (2007, July). "Checking out mentally": Faculty misbehaviors and impact on students. Paper presented at the international conference on Improving University Teaching, Jaen, Spain.

Feldman, K. A., \& Newcomb, T. M. (1996). The impact of college on students (Vol. 2). San Francisco, CA: Jossey-Bass.

Fusani, D. S. (1994). "Extra-class" communication: Frequency, immediacy, self-disclosure, and satisfaction in the student-faculty interaction outside the classroom. Journal of Applied Communication Research, 22(3), 232-255. doi:10.1080/00909889409365400

Garko, M. G., Kough, C., Pignata, G., Kimmel, E. B., \& Eison, J. (1994). Myths about student-faculty relationships: What do students really want? Journal on Excellence in College Teaching, 5(2), 51-65.

Geertz, C. (1983). Local knowledge. New York, NY: Basic Books.

Kearney, P., Plax, T. G., \& Burroughs, N. F. (1991). An attributional analysis of college students' resistance decisions. Communication Education, 40(4), 325-342. doi:10.1080/03634529109378858

Kearney, P., Plax, T. G., Hays, L. R., \& Ivey, M. J. (1991). College teacher misbehaviors: What students don't like about what teachers say or do. Communication Quarterly, 39(4), 309-324.

Kelly, L., Keaten, J. A., \& Finch, C. (2004). Reticent and non-reticent college students' preferred communication channels for communicating with faculty. Communication Research Reports, 21(2), 197-209. doi:10.1080/08824090409359981

Kelsey, D. M., Kearney, P., Plax, T. G., Allen, T. H., \& Ritter, K. J. (2004). College students' attribution of teacher misbehaviors. Communication Education, 53(1), 1-17. doi:10.1080/0363452032000135760

Kuh, G. D., Kinzie, J., Schuh, J. H., \& Whitt, W. (2005). Student success in college: Creating conditions that matter. San Francisco, CA: Jossey-Bass.

Light, R. J. (2001). Making the most of college: Students speak their minds. Cambridge, MA: Harvard University Press.

Manning, K. (1997). Authenticity in constructivist inquiry: Methodological considerations without prescription. Qualitative Inquiry, 3(1), 93-115. doi:10.1177/107780049700300105 
McKeachie, W. J., \& Svinicki, M. (2010). McKeachie's teaching tips: Strategies, research, and theory for college and university teachers (13th ed.). Boston, MA: Houghton Mifflin.

McPherson, M. B., Kearney, P., \& Plax, T. G. (2003). The dark side of instruction: Teacher anger as norm violations. Journal of Applied Communication Research, 31(1), 76-90. doi:10.1080/00909880305376

McPherson, M. B., Kearney, P., \& Plax, T. G. (2006). College teacher misbehaviors. In T. P. Mottet, V. P. Richmond, \& J. C. McCroskey (Eds.), Handbook of instructional education: Rhetorical and relational perspectives (pp. 213-234). Needham Heights, MA: Allyn \& Bacon.

Meyers, S. A. (2009). Do your students care whether you care about them? College Teaching, 57(4), 205-210.

Myers, S. A. (2002). Perceived aggressive instructor communication and student state motivation, learning, and satisfaction. Communication Reports, 15(2), 113-121.

Nadler, M. K., \& Nadler, L. B. (2001). The roles of sex, empathy, and credibility in out-of-class communication between faculty and students. Women's Studies in Communication, 24(2), 241-261. doi:10.1080/07491409.2001.10162436

Richmond, V. P., Gorham, J. S., \& McCroskey, J. C. (1987). The relationship between selected immediacy behaviors and cognitive learning. In M. L. McLaughlin (Ed.), Communication yearbook 10 (pp. 574-590). Thousand Oaks, CA: Sage.

Schoenfeld, A. C., \& Magnan, R. (2004). Mentor in a manual: Climbing the academic ladder to tenure (3rd ed.). Madison, WI: Atwood.

Schrodt, P. (2003). Students' appraisals of instructors as a function of students' perceptions of instructors' aggressive communication. Communication Education, 52(2), 106-121. doi:10.1080/03634520302468

Schroeder, C. (2003, March/April). How are we doing at engaging students? Charles Schroeder talks to George Kuh. About Campus, 8(1), 9-16.

Van Manen, M. (1990). Researching lived experience. Albany: State University of New York Press.

Waldeck, J. H., Kearney, P., \& Plax, T. G. (2001). Instructional and developmental communication and theory and research in the 1990s: Extending the agenda for the 21 st century. In W. B. Gudykunst (Ed.), Communication yearbook 24 (pp. 206-229). Thousand Oaks, CA: Sage.

Wanzer, M. B., \& McCroskey, J. C. (1998). Teacher socio-communicative style as a correlate of student affect toward teacher and course material. Communication Education, 47(1), 43-52. doi:10.1080/03634529809379109 